\title{
Correction to: Periodic inundations drive community assembly of amphibious plants in floodplain lakes
}

\author{
Xueqin Liu $(\mathbb{D} \cdot$ Saibo Yuan · Hongzhu Wang
}

Published online: 22 October 2020

(C) Springer Nature Switzerland AG 2020

Correction to: Hydrobiologia

https://doi.org/10.1007/s10750-020-04401-z original article has been corrected and the correct display of Table 1 is also published here.

Due to an unfortunate mistake during the production process, some rows in Table 1 were distorted. The

Table 1 Biological traits used to calculate functional diversity indices of amphibious plant communities in this study

\begin{tabular}{llll}
\hline Trait & Type of variable & Values or range & Units or categories \\
\hline Life span & Categorical & 2 categories & Annual, perennial \\
Rhizome & Binary & 2 categories & Presence, absence \\
Maximum shoot length & Continuous & $10-400$ & $\mathrm{~cm}$ \\
Rooting depth & Categorical & 3 categories & Shallow $(<20 \mathrm{~cm})$, middle $(20-40 \mathrm{~cm})$, deep $(>40 \mathrm{~cm})$ \\
Specific leaf area & Continuous & $96.3-722.2$ & $\mathrm{~cm}^{2} / \mathrm{g}$ \\
Optimal soil moisture & Continuous & $6.4-62.9$ & $\%$ \\
\hline
\end{tabular}

The original article can be found online at https://doi.org/10.1007/s10750-020-04401-z.

X. Liu $(\bowtie) \cdot$ S. Yuan $\cdot$ H. Wang

State Key Laboratory of Freshwater Ecology and Biotechnology, Institute of Hydrobiology, Chinese Academy of Sciences, Wuhan 430072, China e-mail: xqliu@ihb.ac.cn

S. Yuan

Wuhan City Flood Control Survey and Design Institute

Limited Company, Wuhan 430014, China

Publisher's Note Springer Nature remains neutral with regard to jurisdictional claims in published maps and institutional affiliations. 